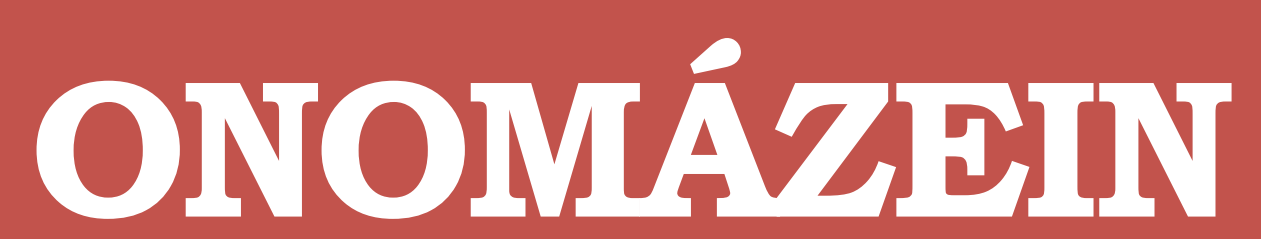

Journal of linguistics, philology and translation
PONTIFICIA UNIVERSIDAD CATÓLICA DE CHILE FACULTAD DE LETRAS

\title{
Enhancing thematic competence by exposure to professional discourse in economic translation ${ }^{1}$
}

\section{Ondrej Klabal}

Palacký University Olomouc

\section{Michal Kubánek}

Palacký University Olomouc

Special

Issue

$-\mathbf{V}-$

Current trends in business translation

2019
ONOMÁZEIN

Special Issue $\mathrm{V}$ - Current trends in business translation: 78-93 DOI: 10.7764/onomazein.tradecneg.03 ISSN: 0718-5758

\section{(C) $\bigodot_{\mathrm{BY}} \bigodot_{\mathrm{ND}}$}

Ondrej Klabal: Palacký University Olomouc, Department of English and American Studies. | E-mail: ondrej.klabal@upol.cz

Michal Kubánek: Palacký University Olomouc, Department of English and American Studies. | E-mail: michal.kubanek@upol.cz 


\section{Abstract}

This paper discusses a situation in a course on economic translation for BA students, and tries to show how exposure to professional discourse helps master the "lingo" of the professional community. An experiment was carried out to show what impact, if any, exposure to professional discourse has on the terminological and phraseological quality as well as on the overall acceptability of translation in this domain. In controlled classroom settings, students were assigned to translate a text on macroeconomic outlook from English to Czech. The first group of participants was asked to translate the text immediately. The second group was first exposed to three TV interviews on the same topic, and then asked to translate the text. The third group was presented with three newspaper articles on the same topic, and then asked to translate the text. The student translations were then assessed with respect to selected rich points to see if there were any differences between the groups. The results suggest that exposure to professional discourse in written form increases the use of idiomatic terminology and phraseology as well as the overall acceptability of the translation while the oral form only increases the overall acceptability of the translation. The potential of using such exercises in specialized translation classroom is discussed.

Keywords: economic translation; professional discourse; thematic competence; trainee translators.

1 Acknowledgement: This study has been supported by Grant of the Czech Ministry of Education, Youth and Sports No. IGA_FF_2019_031 (International Academic Competences in Anglo-American Literary Science, Linguistics and Translation Studies). 


\section{Introduction}

A market survey (Svoboda, 2011) shows that translation in the field of economics and banking is the second most frequent specialization on the Czech market, therefore it is logical that a module on economic translation is an integral part of translation training. At Palacký University Olomouc, Czech Republic, where the authors of this paper are based, this module has a form of a one-semester course on both legal and economic translation².

Over the years that we have taught the course, we have made two observations. Firstly, despite the increasing availability of resources, not only for economic translators, the translations submitted by our trainees still do not read like a commentary written by an economist for a newspaper nor sound like an interview with an economist on TV; in other words, they lack the phraseology used by economists as well as their ease of reasoning. This poses a problem for a translator trainer because in the future the students will "make a living pretending to be (or at least to speak or write as if they were) licensed practitioners of professions that they have typically never practiced" (Robinson, 2003: 128). Therefore, it is necessary that they master the professional "lingo" of the respective professional community, so that their translations pass unnoticed and do not give an impression of a text prepared by an outsider. In theoretical terms, this implies the "covert" or "domesticating" translation approach (cf. House, 1997; Venuti, 1995). Secondly, we have noticed that the "general culture" of students who are mostly recent secondary-school graduates is less and less solid. This is a striking observation as well because already in 2001, Mayoral Asensio noted that "the general culture is becoming more and more specialized" (2001: 313). In fact, such a lack of general culture and lack of curiosity is even more striking given that a high level of general knowledge is considered to be a prerequisite for translators and interpreters. We believe that an understanding of the macroeconomic situation of today's world and of one's own country is undoubtedly part of such a general knowledge of culture. However, a survey among students participating in our experiment showed that three quarters of them follow economic issues only occasionally or seldom.

Taking these two observations as a point of departure, we try to show whether exposing trainee translators to professional discourse in the area of economics can help overcome the outlined problems.

2 The combination of these two fields is common at other universities as well (e.g. Universidad de Granada, Universidad de Málaga, Kent State University).

3 Translated from Spanish by the authors. 


\section{Thematic competence of an economic translator}

For any specialized translator, thematic competence 4 is of paramount importance. The original version of the EMT Competences Framework (EMT Expert Group, 2009) introduced the model of specialized translation competence, of which thematic competence was an integral part. Interestingly, a revised version of the model (EMT Board, 2017) has eliminated thematic competence and subsumed it under "Translation Competence". The 2017 model gives no explanation as to why this reshuffling has taken place. We maintain that thematic competence is different than pure translation competence because it includes knowledge not necessarily related to translation, and making thematic competence a second-order one may seemingly lessen its importance. Therefore, we would support the original version of the model. No matter how thematic competence is positioned in relation to other competences, however, it must be part of translation training and must be enhanced in translation classroom.

The components of thematic competence (EMT Expert Group, 2009: 7) are as follows:

- Knowing how to search for appropriate information to gain a better grasp of the thematic aspects of a document.

- Learning to develop one's knowledge in specialist fields and applications (mastering systems of concepts, methods of reasoning, presentation, controlled language, terminology, etc.) (learning to learn).

- Developing a spirit of curiosity, analysis and summary.

While the first component may overlap with the information-mining competence, the other two constitute thematic competence proper. We believe that it is no coincidence that terminology, which is very often considered the key feature of specialized translation, is only one example of specialized knowledge. What is equally important is the system of concepts or the methods of reasoning. It is, for example, not that difficult to find an equivalent for the term interest rate in the target language. But the translator should also understand what interest rate means, who sets it, and how it may affect economic growth or whether it is good or bad for a particular group of people in a given situation. This enables the translator to differentiate between the reasoning of industry representatives on the one hand and consumers on

4 Other models call this component of translation competence differently. For example, the 2003 PACTE model works with "extralinguistic sub-competence", which is predominantly declarative knowledge, both implicit and explicit, about the world in general, and field-specific (cf. PACTE Group, 2017); Cao (1996: 328) refers to translational knowledge structures, and Krüger (2015: 68) or Salevsky and Müller (2011: 118) use the term "subject-matter competence". 
the other, to give an example. Last but not least, a spirit of curiosity is a must for translators, who never know what will come up in the next translation assignment.

There are several ways trainee translators may acquire thematic competence. Leaving aside an economics degree obtained in a specialized course of study, which is rather infrequent in our context, the main distinction made by Gile (2009: 131-144) when discussing knowledge acquisition in written translation is between terminological and non-terminological or indirect sources. The former include dictionaries (bilingual/monolingual), glossaries and terminology files, and are used to better understand the referents of the terms encountered in the text, their use and translingual equivalents. The latter, i.e. indirect sources (e.g. thematic articles, books, catalogues), are designed for other purposes than terminological research, but they may be used to look up terminology as well (Gile, 2009: 132) and in a way may provide better results because they show terms in their natural context.

This basic classification may be complemented by an overview of sources for economic translators by Pizarro Sánchez (2010: 137-154), who mentions portals and search engines, specialized monolingual and bilingual dictionaries, terminological databases, economic encyclopedias, corpora, general dictionaries and encyclopedias, parallel texts, and other resources, including economic and business newspapers and magazines. While some of the resources are rather terminological sources, others could be used to understand not only the terminology, but also the subject-matter, the phraseology and the discourse. These include parallel texts, whose role in specialized translation has been discussed e.g. by Gallego-Hernández (2017) or Barceló Martínez (2018), or DIY corpora, which are argued by Scott (2012) in relation to legal translation to help acquire the "lingo" of the respective field or genre. In our study, we focus on the role of newspaper articles and TV interviews, i.e. what Pizarro Sánchez above considers complementary resources. Nevertheless, unlike a glossary or a dictionary, they provide access to professional discourse and offer a way to overcome both of the problems discussed in the introduction.

\section{Professional discourse in translator training}

The role of discourse in translator training has been stressed since the seminal monograph by Hatim and Mason (1990). As it is one of the concepts which resist precise definition and are used by various authors to mean various things, we work with the concept of professional discourse defined by Gunnarsson as "text and talk - and the intertwinement of these modalities - in professional contexts and for professional purposes" (2009: 5). Such text and talk is always produced by professionals and may be intended for other professionals with the same or different expertise, for semi-professionals (e.g. learners), as well as non-professionals. According to Gunnarsson (2009: 5-6), professional discourse is key for the construction of knowledge related to the specific domain, economics in our case, and the language and discourse used 
by experts in one field makes it possible to distinguish them from experts in other fields. Thus, professional discourse is owned by the members of the specific discourse community, i.e. economists in our case. In line with what has been stressed above in relation to the thematic competence, professional discourse includes not only terminology, but also text genres and conversation patterns that differ from domain to domain (cf. Gunnarsson, 2009: 6).

A question then arises as to how to make and help students master the professional discourse of the community they are writing for. In their professional life they "will be writing in a field and for a target group which use a sociolect (...) closely related to general language but not identical to it" (Gile, 2009: 131) and the acquisition of such a sociolect should be supported through a structured analytical approach. For legal translation, such an approach has been developed and successfully used by Way (2012). Her model is based on Fairclough's (1992) approach to discourse (see Figure 1 ).

\section{FIGURE 1}

Relation of translation, text, discursive and social practice adapted from Way (2012)

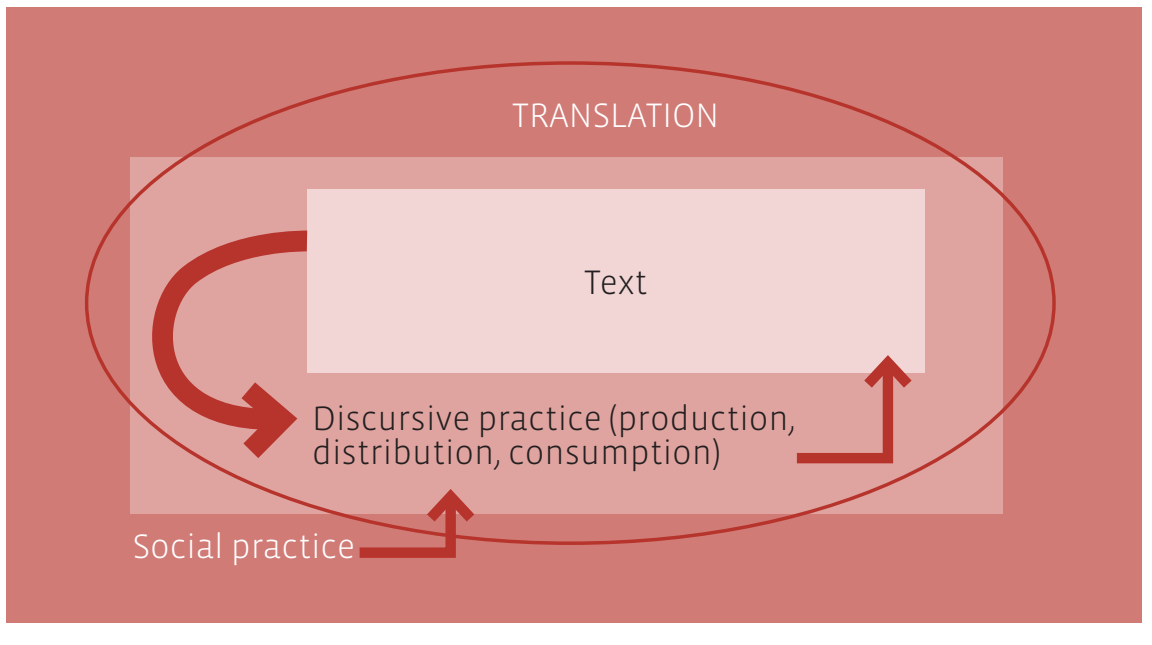

Figure 1 clearly shows that the translation should not encompass only the text itself, which includes the linguistic means used in the text, be they lexical, grammatical or others. The discursive practice, according to Fairclough (1992: 3), "specifies the processes of text production and interpretation"; for example, which discourses are drawn upon and how they are combined together. Lastly, the social practice dimension deals with "issues of concern in social analysis such as the institutional and organizational circumstances of the discursive event and how that shapes the nature of the discursive practice" (Fairclough, 1992: 3).

Way (2012) describes in detail how she applies the model in the translation classroom and argues that translation trainees must first understand the social events and processes which surround the target text, and then locate the text in the discursive practice, which helps them 
internalize social structures and conventions governing the text. Only then should they start working with the text as such. Way (2012: 55) argues that the use of the model in her classroom helps students dissipate many of the potential problems detected in the source text, shift away from word and term focus, and thus not refer to a dictionary as the primary source. Last but not least, the approach helps overcome the hurdle of lack of life experience, which is present in many specialized translation classrooms since most BA students have, e.g., no interest in current interest rate levels as they have not yet taken out a mortgage, or do not follow exchange rate fluctuations as they do not export any goods abroad. In our study we test a less robust approach of using (professional) discourse in a translation classroom, but we believe that it may show some of the benefits as discussed by Way (2012).

\section{Methods}

The experiment was conducted in one go-minute class under controlled conditions. It consisted of a short demographic survey, exposure to professional discourse in Czech presenting the predictions of macroeconomic development in the Czech Republic, and translation of a text from English to Czech on the same topic. To ensure homogeneity of the study sample, twenty-one students who enrolled in the BA Translation and Interpreting Program in the same year participated in the study. The subjects worked anonymously under numbers of their own choice. The initial demographic survey collected information related to the students' experience, asking about the total volume of already translated texts, the portion of economic texts in particular, and their interest in economic issues. Each of the five answer options for these three questions was assigned an incremental value between 0 and 4 , and the total experience score was calculated for each student with 12 points maximum to compare it with the overall result of the translation task (see Annex).

The students were then separated randomly into three groups of seven students each and brought into three computer labs. The first group received no initial exposure to professional discourse. The second group was asked to watch and listen to three TV interviews totaling 15 minutes in length. The interviews featured the Governor of the Czech National Bank, the President of the Czech Chamber of Commerce, and the President of the Czech Trade Unions. The third group was asked to read three newspaper articles totaling 1,900 words in 15 minutes. The articles were written by leading Czech economists, not just economic journalists. After the 15-minute exposure slot, the exposure materials were no longer available to the students.

Following the listening and reading exposure, all three groups were asked to translate an extract of 182 words taken from the Economic Outlook for the Czech Republic, which is published twice-yearly by the OECD (2017), from English to Czech. The full extract is included in Figure 2. The translation brief stated that the translation will be published in the Czech 
section of the OECD website. The time for translation was 70 minutes. To maintain ecological validity of the study, the students worked in computer labs with specialized offline dictionaries, unrestricted Internet access, and other translation resources fully available.

\title{
FIGURE 2
}

An extract from the OECD Economic Outlook for the Czech Republic (2017). Terms, verbs, and clauses under investigation (i.e. the rich points) are in bold, underlined, and highlighted in grey respectively

\begin{abstract}
Strong growth will continue in 2018 and 2019, driven by robust private demand and a dynamic external sector. Increasing wages will support household consumption and low interest rates will boost capital investment. Labour shortages will weigh on growth. Historically low unemployment will push inflation above the central bank's $2 \%$ target. Following the removal of the exchange rate floor in April 2017, the value of the koruna has appreciated slightly. Monetary policy should continue to tighten gradually to counter inflation pressures. Given current and expected primary surpluses, the government could boost infrastructure investment and leverage EU funds. Structural policies to reduce labour shortages and raise labour productivity - such as reducing skills mismatches would facilitate faster growth and sustain higher wage levels.

The financial sector is appropriately capitalised, liquid and profitable. However, the low levels of interest rates and strong economic activity have boosted mortgage credit demand and pushed up house prices. Decreased risk weights assigned to mortgage loans in many banks may amplify risks posed by the housing market and associated loans. A change in prudential rules may be needed as a result.
\end{abstract}

After completion, the students' translations were analyzed with respect to seventeen preselected translation problems, or rich points (cf. e.g. PACTE Group, 2005) in three categories. The first category comprises nine terms (in bold in Figure 2) for which there were Czech equivalents mentioned in the TV interviews or in the newspaper articles the students were exposed to. The terms differ in the difficulty of access to their Czech equivalents. While the equivalents of e.g. interest rate or household consumption are easy to find in specialized dictionaries, the translation external sector or exchange rate floor is less straightforward. In the exposure section of the experiment, the students could read equivalents that might be back-translated as foreign trade or foreign demand for the former (these terms being somewhat more specific), and both hear and read equivalents exchange rate commitment or exchange rate interventions for the latter (no metaphorical motivation in these terms).

The second category includes five verbs (underlined in Figure 2) with their respective equivalents again present in the listening and/or reading exposure. The function of verbs is to relate individual concepts specifying their logical connections, and thus help to present the author's train of reasoning. Verbs also contribute to the text smoothness. Within this category, the verb weigh on proved rather challenging. The verbs used by the students in all three groups might be back-translated as influence or impact lacking the feature of negativity 
which is present in the English verb. The exposure materials included suitable equivalents that correspond in English to slow down or put pressure on (listening exposure), and subdue or stifle (reading exposure).

Finally, we decided to include three clauses in the third category (highlighted in grey in Figure 2). All of them require restructuring in Czech, which has relatively free word order, following the logical relations among the presented facts and reasoning. Taking the opening clause as an example, the time information should appear at the beginning as it is already set by the extralinguistic context of the outlook publication while the crucial information about continued growth should be placed in the clause-final position to stress it. Obviously, these clauses could not have direct equivalents in the exposure materials. Nevertheless, it might be argued that exposure to well-structured texts could indirectly help the students produce more acceptable translations in this respect as well.

\section{Results}

In order to quantify and compare the results, the translations were primarily assessed with respect to the rich points described in the previous section. In the first two categories, i.e. terms and verbs, we distinguished two types of satisfactory translation solutions. If for a given rich point an equivalent was used which was present in the listening or reading exposure, such a solution was marked as "congruent". If a different satisfactory equivalent was used, it was marked as "acceptable". The remaining versions were classified as unacceptable solutions. Since for obvious reasons there were no direct "congruent" equivalents for the third category of clauses, all satisfactory solutions were marked as "acceptable" only.

Before presenting the results for individual groups and rich point categories, we have related in Figure 3 the experience score obtained in the initial survey ( 12 points maximum) to the total result of satisfactory solutions (17 points maximum) for each student. The scatter plot suggests first that the groups were not biased with respect to their members' experience and second that there is no linear correlation between experience and the total result.

The comparison of the total results combining the three categories of rich points (Figure 4) shows that both groups with some exposure performed better than the group with no exposure. Putting congruent and acceptable solutions together, both the listening and the reading exposure group scored 82 points while the group without any exposure scored 73 points. The listening exposure group performed better with respect to overall acceptability while the reading exposure group gained higher score for overall congruency.

Presenting the results in individual rich point categories separately (Figure 5), it can be seen that the listening exposure group outperformed the other two groups in the category 


\section{FIGURE 3}

Experience related to the total result for students in individual groups

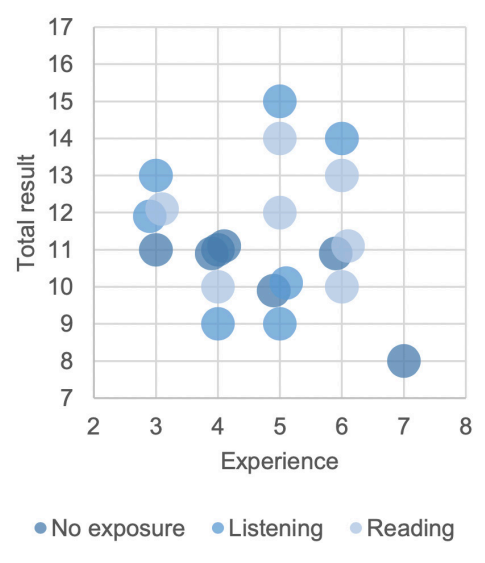

\section{FIGURE 4}

Total results of individual groups

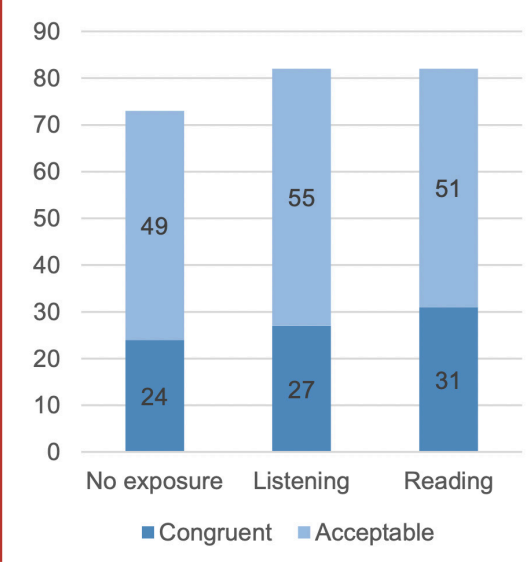

of verbs by using higher number of congruent as well as acceptable equivalents. On the other hand, the reading exposure group gained the highest score in the category of terms by using more congruent equivalents. It also performed slightly better in the category of clauses producing marginally more acceptable solutions.

After assessing all rich points in all translations, the translations were de-anonymized and the degree of congruency with the exposure modality was determined (Figure 6). In other words, we established the proportion of equivalents used by the listening exposure group that also appeared in the TV interviews they had listened to and the proportion of equivalents used by the reading exposure group that also appeared in the newspaper articles they had read. The students must have arrived at the rest of the equivalents marked as congruent using other resources. 


\section{FIGURE 5}

Results in individual rich point categories

Terms

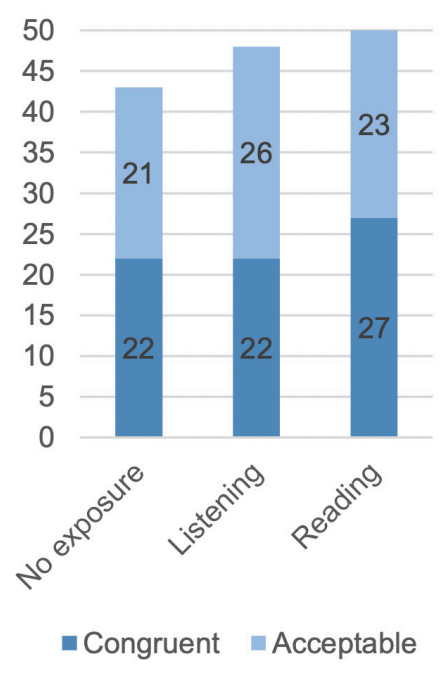

Verbs

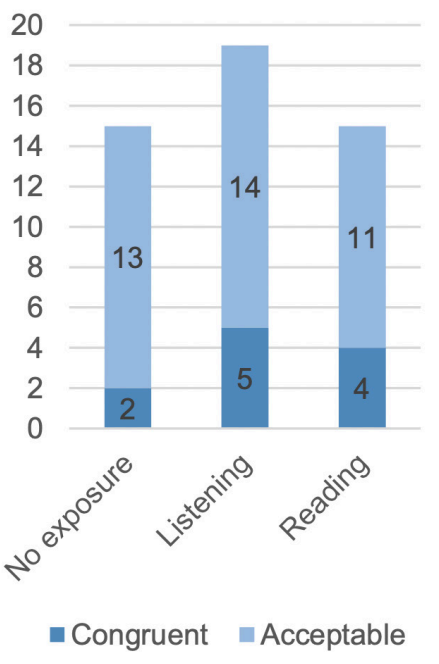

Clauses

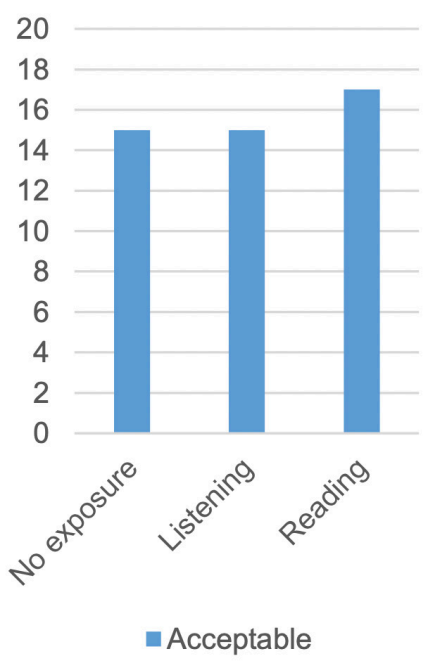

\section{FIGURE 6}

The proportion of equivalents in individual groups congruent with their respective exposure modality
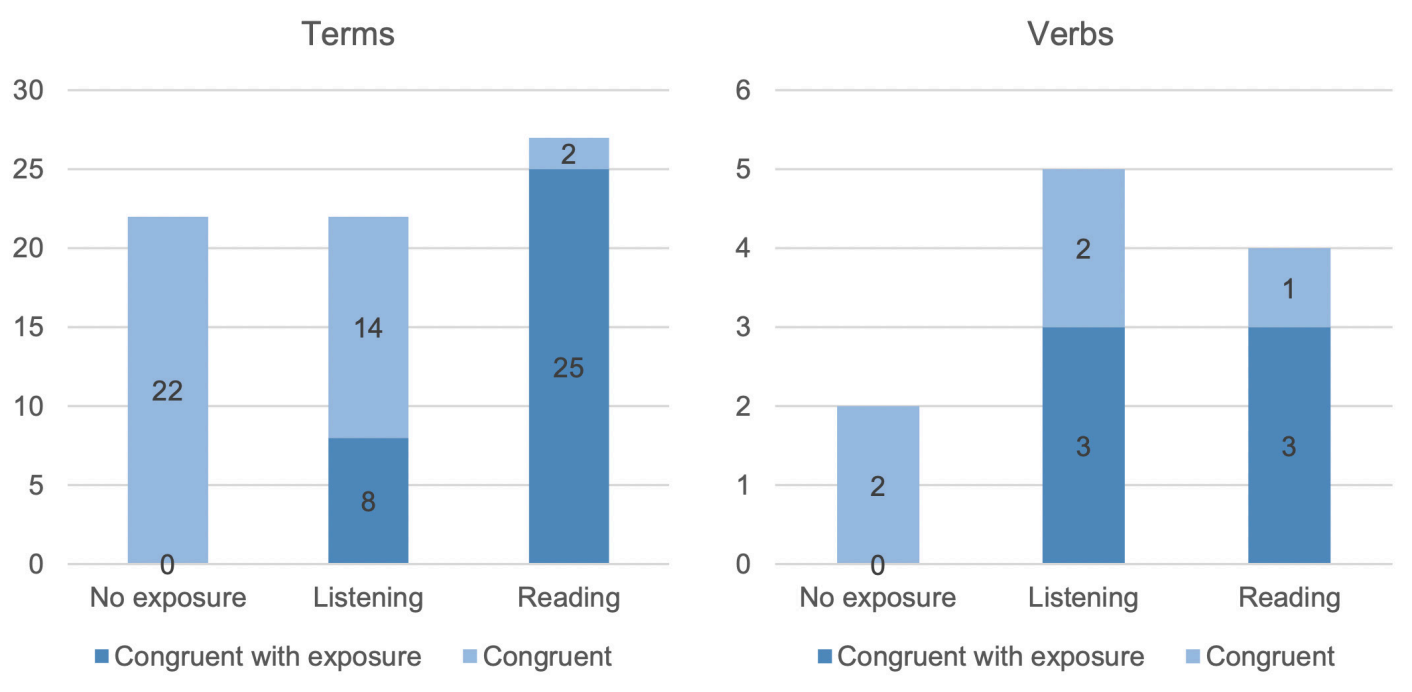

Since the first group had no exposure, there are no equivalents marked as congruent with exposure. The most significant difference between the listening and the reading exposure group can be seen in the category of terms in which much higher number of equivalents were congruent with the exposure modality within the reading exposure group. In the category of verbs, both exposure groups gained higher scores compared to the no exposure group 
with the same number of equivalents congruent with their respective exposure modality. Nevertheless, it should be noted that the numbers are quite low in this category making the quantitative analysis less sound.

\section{Conclusions}

The previous section has shown that while short-term exposure to written professional discourse (reading exposure) seems to increase the use of idiomatic terminology and phraseology as well as overall acceptability of translation, short-term exposure to oral professional discourse (listening exposure) seems to increase the overall acceptability of translation only. Trainee translators may be able to benefit more from written input when it comes to solving terminological issues because they may be used to concentrating on or even highlighting important terms in texts. On the other hand, the results suggest that oral input enhances their translations with respect to the usage of verbs which function as the linking and relation expressing elements because, while listening, students may concentrate more on the overall message of the speech.

Given the sample size and the length of exposure, it must be stressed that the results as well as conclusions presented above are only tentative. A higher number of subjects would definitely increase the reliability and validity of the results; nevertheless the homogeneity of the study sample would be compromised. We believe that the difference could be more significant if the exposure to professional discourse had been long-term (e.g. following the economic news through the entire semester), or if professional translators had been subjected to a similar experiment (as professional translators usually have more life experience, they would be more likely to integrate what they read or heard into their existing knowledge structures, and thus would be able to use the knowledge more actively). In the case of students, it could be argued that what is enhanced is their passive knowledge (recognition), rather than active knowledge (retrieval) as differentiated by Muñoz Martín (2009: 26). This could explain the overall higher acceptability of translations done by students who had had some previous input, so that, when doing their terminological research, some terms or phrases were already familiar to them, and they were able to recognize them. If the study is replicated, a change in these variables could bring different results.

In our opinion, the use of exercises involving professional discourse should be promoted in translation classroom. First, they could be used as activities to acquire and reinforce knowledge. Hurtado Albir (2015) lists the following exercises that can be used to this end: reading support texts and information sheets, debates (in classrooms or online), completing questionnaires. In her opinion, such "tasks allow for the acquisition of different kinds of knowledge related to a unit's objectives, and can also be used as preparation for translating texts" (2015: 265). Support texts could include newspaper commentaries, 
debates could center around recent macroeconomic developments, and questionnaires might concentrate on key pieces of news from the previous night's (economic) news program, or the "terms" used in such a program. What has also proved extremely useful for us are short one-minute news presentations by students subsequently interpreted into the other working language by another student. We believe that the potential of efficiently and effectively working with news in a specialized (economic) translation classroom essentially has no limits (other than limitations of the available class time), and using television (or even radio) news may lead to more interaction. Last but not least, making students follow current news not only enhances the acceptability of their translations, but also makes them more informed citizens, which is undoubtedly also an important role that universities play.

\section{Bibliographic references}

Barceló Martínez, Maria Tanagua, 2018: "Ventajas e inconvenientes de la utilización de textos paralelos en la enseñanza y la práctica de la traducción jurídica”, paper presented at Transius Conference, Geneva, 18th June 2018.

CAO, Deborah, 1996: “A model of translation proficiency”, Target 8 (5), 325-340.

EMT BOARD, 2017: European master's in translation: Competence framework 2017, Brussels: European Commission.

EMT EXPERT Group, 2009: Competences for professional translators, experts in multilingual and multimedia communication, Brussels: European Commission.

FAIRCLough, Norman, 1992: Discourse and social change, Cambridge: Polity.

Gallego-Hernandez, Daniel, 2017: "Testing a methodological framework for retrieving parallel texts in the domain of business translation", Perspectives 25, 1-20.

GILE, Daniel, 2009: Basic concepts and models for interpreter and translator training, revised edition, Amsterdam \& Philadelphia: John Benjamins.

Gunnarsson, Britt Louise, 2009: Professional discourse, London: Continuum.

Hatım, Basil, \& Ian Mason, 1990: Discourse and the translator, London: Longman.

House, Julianne, 1997: Translation quality assessment: a model revisited, Tübingen: Gunter Narr.

Hurtado Albir, Amparo, 2015: "The acquisition of translation competence. Competences, tasks, and assessment in translator training”, Meta 60 (2), 256-280. 
KrÜGER, Ralph, 2015: The interface between scientific and technical translation studies and cognitive linguistics - with particular emphasis on explicitation and implicitation as indicators of translational text-context interaction, Berlin: Frank \& Timme.

Mayoral Asensio, Roberto, 2001: "Por una renovación en la formación de traductores e intérpretes: revisión de algunos de los conceptos sobre los que se basa el actual sistema, su estructura y contenidos", Sendebar 12, 311-336.

Muñoz Martín, Ricardo, 2009: "Expertise and environment in translation”, Mutatis Mutandis 2 (1), 24-37.

OECD, 2017: "Czech Republic", OECD Economic Outlook 2017 (2), Paris: OECD Publishing [available at https://doi.org/10.1787/eco_outlook-v2017-2-14-en, date of retrieval: 10 March 2018].

PACTE Group, 2005: "Investigating translation competence: Conceptual and methodological issues", Meta 50 (2), 609-619.

PACTE Group, 2017: "PACTE translation competence model” in Amparo Hurtado AlbiR (ed.): Researching translation competence by PACTE Group, Amsterdam \& Philadelphia: John Benjamins, 35-42.

Pizarro Sanchez, Isabel, 2010: Análisis y traducción del texto económico inglés-español, Oleiros: Netbiblo.

Robinson, Douglas, 2003: Becoming a translator, second edition, London \& New York: Routledge.

Salevsky, Heidemarie, \& Ina Müller, 2011: Translation as systemic interaction: a new perspective and a new methodology, Berlin: Frank \& Timme.

Scotr, Juliette, 2012: "Can genre-specific DIY corpora, compiled by legal translators themselves, assist them in 'learning the lingo' of legal subgenres?”, Comparative Legilinguistics - International Journal for Legal Communication 12, 87-100.

Svoвoda, Tomáš, 2011: Prüzkum překladatelského trhu, Prague: Institute of Translation Studies. VenUtI, Lawrance, 1995: The translator's invisibility: a history of translation, London: Routledge.

WAY, Catherine, 2012: "A discourse analysis approach to legal translator training", International Journal of Law, Language and Discourse 2 (4), 39-61. 


\section{Annex: Initial demographic survey}

\section{TABLE 1}

Survey questions, answer options and assigned experience values

\section{SURVEY QUESTION}

OPTIONS

ASSIGNED EXP. VALUE

1 - What is the text volume you have translated up to now?

\begin{tabular}{ll}
$0-10$ standard pages & 0 \\
\hline $11-50$ standard pages & 1
\end{tabular}

\begin{tabular}{ll}
\hline $51-100$ standard pages & 2 \\
\hline $101-200$ standard pages & 3 \\
\hline more than 200 standard pages & 4
\end{tabular}

2 - What is the portion of economic texts in the text volume you have translated?

I have never translated economic texts 0

\begin{tabular}{ll}
\hline About one quarter & 1 \\
\hline About one half & 2 \\
\hline
\end{tabular}

\begin{tabular}{|c|c|c|}
\hline \multirow[t]{2}{*}{ have translated? } & About three quarters & 3 \\
\hline & I have translated virtually only economic texts & 4 \\
\hline \multirow{5}{*}{$\begin{array}{l}3 \text { - Do you follow } \\
\text { economic issues? }\end{array}$} & Yes, I am highly interested & 0 \\
\hline & I try to if time allows & 1 \\
\hline & Only occasionally & 2 \\
\hline & Very rarely and randomly & 3 \\
\hline & Not at all & 4 \\
\hline
\end{tabular}

\section{TABLE 2}

Subject options and the total experience score

\begin{tabular}{cccccc} 
GROUP & SUBJECT \# & QUESTION 1 & QUESTION 2 & QUESTION 3 & TOTAL EXP. SCORE \\
\cline { 2 - 6 } & 08 & 2 & 0 & 2 & 4 \\
\cline { 2 - 6 } No exposure & 32 & 3 & 0 & 1 & 4 \\
\cline { 2 - 6 } & 69 & 2 & 1 & 1 & 4 \\
\cline { 2 - 6 } & 77 & 3 & 0 & 2 & 7 \\
\hline & 81 & 3 & 2 & 1 & 5 \\
\hline 93 & 3 & 1 & 0 & 3 \\
\hline
\end{tabular}

5 One standard page is 1800 characters including spaces. 


\begin{tabular}{|c|c|c|c|c|c|}
\hline GROUP & SUBJECT \# & QUESTION 1 & QUESTION 2 & QUESTION 3 & TOTAL EXP. SCORE \\
\hline \multirow{7}{*}{ Listening } & 09 & 3 & 1 & 2 & 6 \\
\hline & 11 & 1 & 1 & 3 & 5 \\
\hline & 31 & 1 & 1 & 1 & 3 \\
\hline & 50 & 1 & 2 & 2 & 5 \\
\hline & 60 & 1 & 1 & 3 & 5 \\
\hline & 64 & 1 & 1 & 1 & 3 \\
\hline & 66 & 1 & 1 & 2 & 4 \\
\hline \multirow{7}{*}{ Reading } & 22 & 2 & 1 & 1 & 4 \\
\hline & 25 & 1 & 0 & 2 & 3 \\
\hline & 33 & 4 & 0 & 1 & 5 \\
\hline & 47 & 3 & 0 & 3 & 6 \\
\hline & 59 & 3 & 1 & 2 & 6 \\
\hline & 68 & 4 & 0 & 2 & 6 \\
\hline & 75 & 4 & 0 & 1 & 5 \\
\hline
\end{tabular}

